\title{
DIREITOS PARA OS ANIMAIS NÃO-HUMANOS? ALGUMAS TEORIAS FILOSÓFICAS A RESPEITO
}

\author{
Non-humans anima rights? Some philosophical theories
}

Recebido:07.03.2018 | Aceito: 27.07.2018

\begin{abstract}
Elísio Augusto Velloso Bastos
Doutor em Direito do Estado pela Faculdade de Direito da Universidade de São Paulo (USP). Professor de Direitos Humanos e de Teoria Geral da Constituição (Graduação) e de Teoria da Constituição: mecanismos de tutela da norma constitucional. A realidade brasileira e amazônica (Mestrado) do Centro Universitário do Pará - CESUPA. Advogado. Procurador do Estado do Pará.E-mail: elisiobastos@oi.com. br. Lattes: http://lattes.cnpq.br/9156547826965478
\end{abstract}

\begin{abstract}
Resumo
O presente trabalho pretende analisar algumas das teorias filosóficas mais relevantes acerca da presença ou ausência de dignidade intrínseca aos animais não-humanos, bem como se tais animais podem ser, ou não, titulares de direitos. $\mathrm{O}$ artigo, assim, deseja identificar algumas das teorias que pretendem responder à pergunta no sentido de qual a efetiva diferença entre os animais, humanos e não-humanos, que fundamente o tratamento profundamente discrepante entre ambos? Partindo de autores que negam a possibilidade de se atribuir direitos aos animais não-humanos, como René Descartes, Immanuel Kant, Ruth Cigman, Alan White e Carl Cohen para, em seguida, apresentar autores favoráveis à referida atribuição, como Jeremy Bentham, Donald Broom, Peter Singer, Tom Regan e Martha Nussbaum, pretende-se elucidar os principais pontos da controvérsia e, com isso, esclarecer um pouco mais o debate. Afinal, há um intenso conflito entre a existência humana, nos moldes em que está assentada, e a efetiva proteção jurídica dos animais não-humanos, já que o reconhecimento de direitos a tais seres certamente implicará em ônus importantes a nós, humanos.
\end{abstract}

Palavras-chave: Animais não-humanos - Dignidade intrínseca - Teorias Filosóficas.

\begin{abstract}
The present work intends to analyze some of the most relevant philosophical theories about the presence or absence of intrinsic dignity to nonhuman animals, as well as whether or not such animals are or are not rights-holders. The article thus intends to identify some of the theories that intend to answer the question in the sense of what the effective difference between the animals, human and nonhuman, that ground the treatment deeply discrepante between both? Based on authors who deny the possibility of assigning rights to nonhuman animals, such as René Descartes, Immanuel Kant, Ruth Cigman, Alan White and Carl Cohen to then present authors favorable to this assignment, such as Jeremy Bentham, Donald Broom, Peter Singer, Tom Regan and Martha Nussbaum, it is intended to clarify the main points of the controversy and thereby to clarify the debate a bit more. After all, there is an intense conflict between human existence, at least in the form in which it is based, and the effective legal protection of non-human animals, since the recognition of rights to such beings will certainly imply important burdens on us, humans.
\end{abstract}


KeYwords: Non-human animals. Intrinsic Dignity. Philosophical Theories.

SumÁRIO: 1. Introdução - 2. Questões Preliminares - 3. Teorias filosóficas relevantes que pretendem identificar a presença ou ausência de dignidade intrínseca aos animais não- humanos - 3.1. A objeção de Immanuel Kant - 3.2. As objeções de Ruth Cigman e Alan White - 3.3. As objeções de Carl Cohen - 3.4. Jeremy Bentham e Donald Broom: Senciência e Bem-estar animal - 3.4.1. Senciência - 3.4.2. Bem-estar - 3.5. Peter Singer e a pretensão pela Libertação Animal - 3.6. Tom Regan e a Dignidade à Vida - 3.7. Martha Nussbaum e as Competências como atributos suficientes para o reconhecimento de direitos aos Animais não-humanos - 4. Conclusão - 5. Notas de Referência.

\section{INTRODUÇÃo}

Temas que preocupam os filósofos desde a antiguidade, o estatuto moral, o valor ou dignidade intrínsecos, o status existencial ou filosófico dos animais não-humanos vêm merecendo, aos poucos, também a preocupação da ciência do Direito e dos ordenamentos jurídicos. Afinal, passo natural e seguinte ao reconhecimento da existência de tais atributos aos animais não-humanos será o reconhecimento ou declaração de que também possuem direitos.

Identificar, pois, qual a diferença entre os animais, humanos e não-humanos, que fundamente o tratamento profundamente discrepante entre ambos tem se revelado uma questão cada vez mais inquietante e oportuna.

Neste sentido, diferentes teorias pretendem identificar ou negar a presença de dignidade intrínseca a tais seres, sendo que ainda predomina um elevado grau de antropocentrismo ou, para alguns, especismo, na visão da relação entre nós, humanos, e referidos animais, visão esta que predominou na elaboração de nossa atual Constituição da República, cujo texto considera a fauna como um "bem de uso comum do povo".

O presente trabalho procurará trazer algumas das principais visões filosóficas acerca do tema, pelo que argumentos de ordem comum (os animais seriam ou não humanos; jamais poderíamos defender a existência de Direitos a seres como as amebas ou as baratas, por exemplo ou mesmo as plantas; os animais não-humanos não respeitariam nossos direitos e sequer entenderiam a linguagem dos direitos...) ou teológica (eventual ausência ou presença de alma nos animais não-humanos; Deus teria ofertado direitos apenas ao humanos; Deus teria ofertado aos humanos o domínio sobre tais animais...) serão tratados em outra oportunidade e podem ser acessados em algumas obras.

Os autores deixam claro, desde logo, fazerem parte do grupo que, ao identificar um valor intrínseco nos animais não-humanos, reconhecem que a titularidade de direitos ultrapassa a categoria ou espécie humana. A visão da Constituição da República de 1988 acerca do tema, as razões que justificam a opção dos autores pelo reconhecimento de direitos aos animais não-humanos, bem como alguns dos efeitos práticos de referida escolha serão abordadas em trabalhos subsequentes. 


\section{${ }_{2}$ Questões Preliminares}

A questão acerca da diferença entre os animais, humanos e não-humanos, que fundamente o tratamento profundamente discrepante entre ambo, em regra, é respondida mediante a análise da racionalidade ou da capacidade de se comunicar, inerentes, em princípio, aos humanos, como salienta, Alasdair Macintyre, pelo que é comum que se discuta a presença ou ausência de dignidade intrínseca a tais seres à luz de habilidades, capacidades ou conhecimentos próprios da espécie humana

Assim, há autores que não identificam traços de dignidade intrínseca nos referidos animais em face de que tais seres seriam incapazes de se comunicar - pelo menos não da forma que os humanos se comunicam - o que inviabilizariam a capacidade de possuir direitos por si só.

Neste sentido, Peter Singer esclarece que em muitos casos a não concessão de direitos aos animais não-humanos está ligada ao argumento da falta de capacidade de retribuir por parte de tais animais (não-reciprocidade), à medida que a ética apenas surgiria a partir do seguinte acordo: "se não o prejudico, você não me prejudicará".

Perter Singer, neste aspecto, assevera que almejar que os animais não-humanos possam gozar de direitos, não significa, exatamente, almejar que gozem dos mesmos direitos que os humanos, mas que gozem de direitos básicos com o de não serem maltratados, abandonados, e isto sequer por que tais práticas seriam desumanas, mas sim por que elas ferem o direito do animal, enquanto possuidor de direitos.

(..)it would be meaningless to attribute to nonhuman animals such rights as the right to vote, to freedom of speech, or to freedom of religion. But then, it is equally meaningless to give such rights to two-year-old humans. That doesn't mean that we should give less weight to the interests that two-year-old humans have, like the interests in being fed, in being warm and comfortable, and in being loved.

Para que se possa fazer um comparativo sobre tal perspectiva, crianças, idosos, e os possuidores de alguma limitação de capacidade (como curatelados, por exemplo), são seres possuidores de dignidade intrínseca e direitos, contudo não possuem a capacidade de votar, de casar, contratar, mudar de cidadania e isso não os faz menos importantes que os outros seres humanos.

Significa dizer que, como o faz James Rachels, em que pese o fato de podermos considerar a existência de racionalidade e autonomia em um indivíduo e, a partir desta consideração, estabelecer algumas diferenças de tratamento com base nestas características, o fato é que nem toda a diferença de tratamento se justifica com base nos mesmos critérios. Parece aceitável, pois, com base em tal racionalidade (ou ausência dela), impedir que animais ou crianças votem, mas será inaceitável sustentar que tais critérios autorizam "pôr químicos em olhos de coelhos para testar a segurança de um novo champô".

Ainda, um dos pontos debatidos quanto à concessão ou não de direitos aos animais não humanos seria a delimitação dos grupos de animais que serão protegidos, eis que os humanos, em regra, não consideramos todos os animais de forma homogênea. Nossa consideração por cães ou gatos, por exemplo, revela-se superior à consideração por formigas, mosquitos ou baratas. Neste sentido, a defesa por direitos aos animais não-humanos não 
leva à conclusão de que as pessoas não podem matar formigas ou mosquitos, ou livrarem-se de ratos e baratas que infestam suas casas, como bem esclarece Cass Sustein.

Desta forma o debate ainda se dá em torno do tipo de animal a qual o direito será direcionado, seriam todos os animais ou apenas alguns, como, por exemplo, os com alguma capacidade de sofrer?

Para respondermos tais perguntas faz-se primordial entendermos um pouco melhor a discussão filosófica concernente a concessão de direitos humanos a animais não-humanos.

\section{TeOrias filosóficas ReleVantes QUE PRETENdEM IDENTIFICAR A PRESENÇA OU AUSÊNCIA DE DIGNIDADE INTRÍNSECA NOS ANIMAIS NÃO- HUMANOS}

\subsection{A ObJeÇão de imMANUel KANT}

Immanuel Kant é, sem dúvida, um dos autores de maior relevância ao estudo da Dignidade Humana. Sucede que para Kant os animais não-humanos seriam desprovidos de dignidade, sendo, em verdade, coisas, não podendo ser, assim, titulares de direitos:

The fact that the human being can have the representation ' $\mathrm{I}$ ' raises him infinitely above all the other beings on Earth. By this he is a person that is, a being altogether different in rank and dignity from things, such as irrational animals, with which one may deal and dispose at one's discretion.

Para Kant, portanto, tais animais estariam à completa disposição dos humanos, pelo que estes apenas teriam deveres morais para com os outros da mesma espécie. Todavia, em que pese serem desprovidos de dignidade, os seres humanos deveriam ter obrigações perante os animais não-humanos. Tais obrigações com os animais não-humanos seriam indiretas para com a humanidade, eis que o modo de tratar tais seres desprovidos de dignidade reforçaria certa tendência de se comportar de modo igual com os humanos.

Henry Salt (1980), destaca que as objeções kantianas têm origem religiosa, pelo que o poder dos Homens sobre os demais animais teria sido ofertado a Noé por ordem expressa de Deus, razão pela qual os homens exerceriam sobre tais seres o mesmo direito que exerceriam sobre as plantas e as pedras, atribuindo-lhes qualquer fim bom e razoável que desejarem, tal como o progresso, o conhecimento, a saúde, etc.

Para Kant a imposição de sofrimento aos animais não-humanos não seria um ato intrinsecamente mal, sob o ponto de vista da moralidade, pelo que apenas seria moralmente reprovável que do ato de impor tal sofrimento decorresse prazer ao homem, porque, se decorresse o prazer, o homem degradaria e embruteceria sua própria natureza. 


\title{
3.2 As objeções de Ruth Cigman e Alan White
}

Ambos os autores posicionam-se de forma contrária à concessão de direitos aos animais não-humanos.

Ruth Cigman defende o que denomina por incapacidade de percepção da morte, pelo que mesmo que os animais não-humanos apresentem sentimento semelhante ao medo, quando são ameaçados e suas vidas correm perigo, não significa dizer que tal sentimento seja interpretado como uma percepção da morte, como um desejo de continuar vivo, mas sim como um reflexo instintivo do animal não humano para sua sobrevivência.

Aos animais não humanos, dessa forma, faltariam o que a autora chama de desejo, o qual não implicaria, apenas, o ato de estar vivo, mas sim à capacidade de responder se deseja ou não permanecer vivo.

Como os animais não teriam a capacidade de desejar, não poderiam ser titulares de direitos, visto que não possuiriam percepção sobre seu futuro, sobre sua vida ou sua morte. Contudo esta ideia trazida pela autora apresenta falhas, já que, como se verá adiante, existem estudos que comprovam que os animais não-humanos possuem certo grau de percepção e compreensão.

Alan White, por seu turno, assevera que para possuir um direito se deve, necessariamente, compreender as implicações de tais direitos, pelo que não se poderia conceder direitos aos animais não-humanos pela falta de entendimento que tais serem teriam sobre o que tais direitos gerariam. Para alguém possuir um direito, mister a exata compreensão das exigências inerentes ao exercício de tal direito.

\begin{abstract}
De um direito, diz-se que é algo para ser exercido, recebido, gozado ou dado, que pode ser declarado, exigido, atribuído, reivindicado, assegurado, renunciado, abdicado; pode haver um direito de fazer isso e aquilo, ou de ter isso ou aquilo feito em favor de alguém, estar em um certo estado, ter uma certa emoção, ou adotar uma certa atitude. Um direito é relativo, e contrapõe-se a um dever, a uma obrigação, a um privilégio, a um poder, a uma responsabilidade. Um sujeito possível de direito é, então, o que propriamente pode ser expresso nessa linguagem, isto é, aquele do qual se pode inteligivelmente dizer, seja verdadeira ou falsamente, que é capaz de exercer, usufruir etc. um direito, ter um direito a tais coisas diversas, ter deveres, privilégios, etc. Além disso, [...] uma condição necessária para que um ser qualquer seja capaz de ter um direito a $\mathrm{V}$ é que seja capaz de $\mathrm{V}$
\end{abstract}

Assim, para o autor é necessário que o destinatário da concessão de direitos cumpra todos os requisitos trazidos supra. Para White a possibilidade de sofrer não seria relevante na concessão de direitos, visto que o ser humano também possui sofrimento e nem todos os sofrimentos destes são passiveis de proteção, já que o homem pode sofrer com a perda de um emprego, por exemplo, e não haveria como o Estado ser responsabilizado diretamente para impedir que tal sofrimento ocorra. Ou seja, cada ser sofre de maneira diferente e subjetiva, não existindo possibilidade de abarcar todas as formas possíveis de sofrimento.

Desta maneira, atribuir um direito a um ser implica afirmar que este possui deveres, obrigações e privilégios decorrentes de tais direitos. Sendo assim, uma teoria com viés contratualistas. Não podendo, então, ser atribuídos direitos a animais não humanos. En- 
tretanto, o fato de não poder ser exigido dos animais não humanos os deveres e obrigações inerentes dos direitos a serem concedidos, não exclui o fato de que os animais não humanos careçam de maior proteção do que a existente atualmente. Sendo assim falha a tentativa de desconsideração pelos motivos expostos pelo autor.

Assim, tanto Cigman quanto White, afirmam que os animais não humanos não podem ser possuidores de direitos, mesmo que por motivos diferentes. A primeira por considerar que não possuem percepção da morte, e consequentemente desejo de viver. E o segundo por considerar que todo direito gera um dever.

\subsection{As Objeções de Carl Cohen}

Carl Cohen é, sem dúvida, um importante crítico à ideia de que os animais não-humanos teriam direitos.

Em uma lógica reconhecidamente consequencialista, assevera que se defendermos esta ideia teríamos de considerar moralmente intoleráveis diversas conquistas na área da saúde, todas apoiadas em pesquisas com animais não-humanos, que salvaram dezenas de milhares de crianças humanas de doenças como difteria, hepatite, sarampo, raiva, rubéola, tétano, AIDS, malária e outras. Afinal, a substituição de animais não-humanos por outros mecanismos, como simulações em computadores ou amostras de tecido não passariam de uma ilusão ou fantasia.

Assim, sustenta que a defesa dos direitos dos animais não-humanos seria um erro gigantesco. Seu ponto de vista está alicerçado, basicamente, no argumento de que o conceito de direito seria essencialmente humano, estando enraizado em um mundo moral humano, apenas tendo força em seu interior.

Neste sentido, Cohen afirma que os animais não-humanos seriam amorais, eis que seriam desprovidos de qualquer ideia de bem ou de mal. Assim, não poderia haver direitos entre eles e, logo, eles não poderiam ter direitos perante os humanos.

Assevera, ainda, que os direitos surgiriam apenas em uma comunidade de seres morais. Assim, critérios como a racionalidade, a capacidade de comunicar-se, a capacidade de sofrer, ou a capacidade de escolher que ações praticar não seriam relevantes para justificarmos que apenas os humanos poderíamos gozar de direitos. O único critério idôneo para esta finalidade seria que apenas nós humanos gozaríamos de autonomia moral, ou seja, capacidade de elaborar a regulação de si mesmo.

Desta forma, apenas os humanos teríamos a capacidade de ser agentes morais, com a capacidade de captar a generalidade das restrições morais que se colocariam em frente à nossa vontade. Por isso estabelecemos leis morais e potencialmente gozamos de autonomia moral. E ainda que os bebês, senis ou os pacientes em coma não possam fazer exigências e juízos morais, o fato é que não seriam as pessoas individuais que se qualificariam (ou não se qualificariam) para a posse de direito em face da presença ou ausência de alguma capacidade específica a tal indivíduo.

Afinal, apenas os seres humanos viveriam vidas que serão, foram ou permanecem essencialmente morais. Neste sentido, não se pode negar que as crianças pequenas potencialmente utilizarão suas moralidades. Que os senis ou as pessoas em como já realizaram suas vidas, anteriormente, mediante a mesma habilidade moral. 
Ainda, afirma Cohen, que negar a existência de direitos aos animais não seria negar a existência de obrigações dos humanos perante tais seres, ou mesmo permitir-nos tratá-los com uma desconsideração insensível. Afinal, teríamos a obrigação de agir humanamente e seria seguramente falso que todas as obrigações decorreriam dos direitos dos outros, pelo que algumas de nossas obrigações mais importantes não teriam qualquer fundamento em direitos, como, por exemplo, as que resultam de compromissos assumidos livremente. Arremata Cohen:

Como professor universitário, aceito a obrigação de comentar minuciosamente os trabalhos dos meus alunos e faço isso, mas eles não têm o direito de exigir que o faça. (...) Os anfitriões têm a obrigação de ser cordiais para os seus convidados, mas o convidado não tem o direito de exigir cordialidade. (...) A minha cadela não tem um direito a exercício diário e a cuidados veterinários, mas eu tenho a obrigação de lhe proporcionar estas coisas.

\subsection{Jeremy Bentham e Donald Broom: Senciência e Bem-estar animal}

Jeremy Bentham, foi um dos percursores da ideia de senciência que até os dias atuais é extremamente debatida e estudada. Buscava estender a capacidade de 'sentir' a todos os animais, humanos ou não humanos. Sua teoria de base utilitarista, proporcionou, grande avanço no estudo ético dos animais não humanos.

Donald Broom, é pesquisador e professor da Universidade de Cambridge e dedicou sua carreira a escrever e pesquisar sobre o bem-estar animal, publicando diversas obras sobre o assunto.

Sendo de grande importância para as teorias relacionadas ao direito dos animais não humanos, faz-se necessário conhecer as teorias da senciência e o bem-estar dos animais não humanos.

\subsubsection{SENCIÊNCIA}

Jeremy Bentham esclarecia, já em 1789, a importância do conceito denominado "senciência", a qual identificou como sendo a capacidade de sofrer dos animais:

The day may come when the rest of the animal creation may acquire those rights which never could have been withholding from them but by the hand of tyranny. The French have already discovered that the blackness of the skin is no reason why a human being should be abandoned without redress to the caprice of a tormentor. It may one day come to be recognized that the number of the legs, the villosity of the skin, or the termination of the sacrum, are reasons equally insufficient for abandoning a sensitive being to the same fate. What else is it that should trace the insuperable line? Is it the faculty of reason, or perhaps the faculty of discourse? But a full-grown horse or dog is beyond comparison a more rational, as well as more conversable animal, than an infant of a day, or a week, or even a month, old. But suppose they were otherwise, what would it avail? The question is not, Can they reason? nor Can they talk? but, Can they suffer? 
Para Bentham, portanto, o que seria relevante para a concessão de direitos aos animais não-humanos não seria sua capacidade de raciocínio, muito menos sua habilidade de falar, mas sim sua capacidade de sentir, principalmente dor e sofrimento. Asseverava, ainda, que não deveríamos discriminar outro ser vivo somente por suas características físicas, pelo que a capacidade de sentir ou de sofrer é a que determinaria a proteção do ser, e não somente a racionalidade.

Em consoante com tal afirmação de que animais possuem senciência, temos The Cambridge Declaration on Consciousness, escrita por Philip Low, que traz consigo a concepção de que além da senciência, os animais não humanos também podem ter - em certo grau - consciência. Veja-se:

We declare the following: "The absence of a neocortex does not appear to preclude an organism from experiencing affective states. Convergent evidence indicates that non-human animals have the neuroanatomical, neurochemical, and neurophysiological substrates of conscious states along with the capacity to exhibit intentional behaviors. Consequently, the weight of evidence indicates that humans are not unique in possessing the neurological substrates that generate consciousness. Nonhuman animals, including all mammals and birds, and many other creatures, including octopuses, also possess these neurological substrates"

A declaração de Cambridge sobre consciência foi escrita por Philip Low e editada por Jaak Panksepp, Diana Reiss, David Edelman, Bruno Van Swinderen, Philip Low e Christof Koch. Foi proclamada publicamente em Cambridge, em julho de 2012. Partiu do estudo de treze cientistas, dentre eles neurocientistas, neurofarmacologistas e neuroatomistas, com o intuito de provar que animais possuem certo nível de consciência.

Tais pesquisadores depararam-se com algo que os surpreendeu, que provaria que não só os animais têm consciência, mas que alguns apresentam níveis semelhantes ao nosso.

Para entender a capacidade dos animais de apresentar consciência e algumas características que encontramos primordialmente em seres humanos, Lori Gruen fala-nos acerca de um caso ocorrido na Nova Zelândia, em 2004, onde um grupo de golfinhos, aparentemente pretendendo proteger aqueles que consideraram vulneráveis, teria protegido alguns nadadores de um ataque de tubarão.

Contudo a percepção da sociedade, mesmo com os diversos estudos científicos existentes ao longo do tempo, em relação a quais animais não humanos consideram possuidores de algum grau de senciência varia no tempo e de acordo com a sociedade em que estão inseridos tais animais não humanos:

A opinião humana em relação a quais indivíduos são sencientes vem, em geral, apresentando alterações ao longo do tempo em sociedades bem instruídas, para englobar em primeiro lugar todos os seres humanos ao invés de apenas um subgrupo destes e, então, certos mamíferos desde sempre mantidos como animais de companhia, animais que pareciam ser mais similares aos seres humanos, como os macacos, os mamíferos maiores, todos os mamíferos, todos os animais de sangue quente, e, então, todos os vertebrados. O público em geral tem demonstrado estar preparado para aceitar alguma orientação à cerca da evidencia de senciência mostrada por biólogos, os quais vem coletando informações sobre as habilidades e funcio- 
namento dos animais. Os animais que demonstram complexidade de organização, capacidade de aprendizagem sofisticada e atenção geralmente são mais respeitados que aqueles que não apresentam tais características, e têm menor risco de ser maltratados. Entretanto, algumas pessoas veem os animais somente com base nos seus efeitos sobre, ou valor percebido (extrínseco) para, os seres humanos, apresentando pequena preocupação pelo bem-estar de pestes, portadores de doenças ou aqueles que não podem ser consumidos.

Desta forma, para o ser humano, seria mais fácil aceitar que animais não-humanos, que possuem semelhanças conosco, são dotados de senciência. Sendo a capacidade de sentir, que está presente nos animais vertebrados, melhor aceita.

Assim, as experiências sentidas pelos seres humanos também seriam sentidas pelos animais não-humanos analogamente. Não seriam os mesmos sentimentos, mas análogos. Os seres humanos precisariam parar de tentar humanizar os sentimentos dos outros seres, não seriam, pois, idênticos, mas percebidos de maneira diversa.

Destarte, para identificar o que seria considerado sentimento para os animais não-humanos bem como quais as diferenças entre o que eles sentem e o que os humanos sentimos, criou-se uma ciência que pretende permitir a medição dos níveis de bem-estar dos seres sencientes.

3.4.2 BEM-ESTAR

A humanização das necessidades dos animais não humanos somente satisfaz o que o homem considera como necessário e conveniente, e não o que o animal não-humano realmente precisa. Ele não possui os mesmos desejos e vontades que o ser humano, nem os mesmos objetivos. Satisfazendo o que o homem considera melhor, muitas vezes estará frustrando o que proporcionaria o bem-estar desse animal.

Um cachorro não ficará deprimido pelos mesmos motivos que os humanos ficamos, ele não tem as mesmas interações sociais que os humanos temos, ele ficará triste, por exemplo, se seu 'dono' morrer, mas não porque o 'dono' perdeu o emprego ou teve algum fracasso nos negócios. Para entendermos melhor o comportamento dos animais não humanos, faz-se necessário que entendamos a ciência do bem-estar, e de onde surgiu:

A ciência do bem-estar animal desenvolveu-se rapidamente nos anos 1980 e 1990, e tem-se demonstrado importante a separação entre ciência e julgamento moral. A avaliação do bem-estar pode ser realizada de maneira objetiva, inteiramente independente de quaisquer considerações morais. (...). Nosso conhecimento de cada um desses indicadores de bem-estar vem se aprimorando rapidamente nos últimos anos, à medida que pesquisadores com conhecimento em zoologia, fisiologia, psicologia, criação de animais e medicina veterinária têm investigado os efeitos de condições difíceis sobre os animais.

Desta forma, pretende-se que o bem-estar animal seja medido livre de julgamentos morais, devendo ser analisados os indicadores por ele trazidos e aplicá-los da melhor maneira possível, visto que são medidores científicos. O que poderá possuir julgamento moral 
serão os níveis aceitáveis de diminuição do bem-estar, que deverá ser julgado de acordo com cada caso, e com isso poderá sofrer variações.

A princípio teríamos os indicadores de bem-estar que serviriam para definir a positividade ou negatividade dos sentimentos dos animais não-humanos. Contudo, assim como os sentimentos dos seres humanos, os dos tais seres também seriam difíceis de medir com precisão já que poderia haver diversas variações. Quanto aos medidores de bem-estar iniciais, seriam eles:

- Indicadores fisiológicos de prazer;

- Indicadores comportamentais de prazer;

- Extensão na qual comportamentos altamente preferidos podem ser demonstrados;

- Variedade de comportamentos normais demonstrados ou suprimidos;

- Extensão na qual processos fisiológicos e desenvolvimento anatômico normais são possíveis;

- Extensão de aversão comportamental demonstrada;

- Tentativas fisiológicas de se adaptar;

- Imunossupressão;

- Prevalência de doenças;

- Tentativas comportamentais de se adaptar;

- Doenças comportamentais;

- Alterações cerebrais;

- Prevalência de danos físicos;

- Habilidade reduzida de crescer ou se reproduzir;

- Redução da expectativa de vida (BROOM, FRASER, 2007, p. 58)

Para se analisar esses medidores seriam aplicados métodos científico de pesquisa, por intermédio de medição de frequência cardíaca, exames de sangue, exames realizados após atividades físicas, exames de estresse, entre outros meios. Contudo tais indicadores seriam mais utilizados em animais domésticos de produção, mas poderiam ser utilizados para os demais animais não-humanos.

Seria, assim, necessário que se analisasse os níveis de bem-estar dos animais, observando os indicadores trazidos anteriormente, analisando, assim, se seriam satisfatórios, para, desta forma, garantir o bem-estar dos animais não-humanos.

Em relação aos animais domésticos de companhia, seriam vedados procedimentos como: castração, cortes de cauda, orelha ou unha, modificação genética de raças, e alguns casos de castração, dentre outros que mais estariam preocupados com o bem-estar dos humanos do que, propriamente, dos animais que sofrem tais procedimentos.

A questão é bem mais sensível se analisarmos os casos que envolvem os animais de produção, os quais, sequer desenvolveriam uma relação de afeto com sues "donos". Justamente por isso foram definidas cinco liberdades quer pretendem nortear a relação dos hu- 
manos com tais animais de produção, garantindo padrões razoáveis de bem-estar animal. São elas a Liberdade de fome e sede, a Liberdade de desconforto, a Liberdade de dor, lesões e doenças, a Liberdade de medo e stress e a Liberdade para expressar seu comportamento natural.

\subsection{Peter Singer e a pretensão pela Libertação Animal}

Peter Singer é um dos principais responsáveis pelo moderno movimento que pretende ofertar, aos animais não-humanos, a titularidade de direitos. Na década de 70 do século passado tornou-se um de seus principais ativistas.

Singer propõe que o direito dos animais não-humanos decorre de sua capacidade de sentir dor e, principalmente, da possibilidade da aplicação do princípio da igual consideração, fazendo um comparativo com o direito das mulheres em sua obra denominada "Libertação Animal". Veja-se:

(...) A extensão do princípio básico da igualdade de um grupo para outro não implica que devamos tratá-los da mesma maneira, ou que devamos conceder-lhes os mesmos direitos. O que devemos ou não fazer depende da natureza dos membros desses grupos. O princípio básico da igualdade não requer tratamento idêntico, mas sim igual consideração por seres diferentes pode levar a tratamentos e direitos distintos.

Desta forma, quando se busca atribuir direitos aos animais não-humanos, não necessariamente se almeja que tenham direitos idênticos aos dos seres humanos, mas sim que sejam tratados com igual consideração. Não se trataria, pois, de tratamento igual, mas de tratamento como igual.

Afinal, existem diferenças entre as espécies que são inegáveis, até mesmo para o autor, e com isso não há que se afirmar que o tratamento com igualdade que se quer buscar advenha das semelhanças existentes entre esses grupos diferentes, mas sim das suas próprias distinções.

Partindo do princípio de que igualdade não é uma afirmação de fato, mas uma ideia moral. Tal ideia independe do pertencimento a determinada raça, do gozo de certo nível de capacidade intelectual ou de força física, pelo que, não haveria qualquer razão lógica para que não fosse concedida ou reconhecida a determinados grupos. Neste sentido, assevera Singer que o princípio da igualdade entre os seres humanos estaria muito mais ligado a uma ideia de dever ser do que, propriamente, de ser. Seria, assim, um conceito em essência prospectivo, e não descritivo, portanto.

O elo para o tratamento isonômico entre os diversos animais, humanos ou não-humanos, seria a senciência, cuja importância assim abordou:

Jamais fiz a absurda afirmação de que não há diferenças significativas entre adultos humanos normais e outros animais. O que afirmo não é que os animais sejam capazes de agir moralmente, mas que o princípio moral da igual consideração de interesses se aplica tanto a eles quanto aos seres humanos. Quase sempre se inclui, na 
esfera da igual consideração, seres incapazes de escolhas morais. Isso está implícito no tratamento que damos a crianças e a outros seres humanos que, por um motivo ou outro, não tem capacidade mental para compreender a natureza de uma escolha moral. Como diria Bentham, o que importa não é se podem escolher, mas se podem sofrer.

Portanto, a capacidade do animal não-humano de sentir seria de extrema relevância em relação a qualquer outro argumento de não concessão de direitos, já que a maioria dos argumentos giram em torno da incapacidade de falar e se comunicar. Assim, o que deve ser levado em consideração é a capacidade de sentir.

Todos os animais, humanos e não-humanos, demonstraríamos, de maneira própria, o medo, a dor, a alegria, o que, para Singer, comprovaria a inerente capacidade de sofrimento e de sentir, defendendo, ademais, que algumas espécies iriam além disso, demonstrando-nos que seriam capazes de algum nível de comunicação, como, por exemplo, no caso da gorila Koko, ainda que de maneira própria e rudimentar.

Para Singer, ademais, existiria uma certa tendência de alguém a favor dos interesses de membros da sua própria espécie, contra os de outras. Tal tendência é denominada, por Singer, de especismo e, assim, é comparada ao racismo, por exemplo.

Haveria, pois, uma ideia de domínio do homem sobre o animal não-humano, que derivaria das mais remotas interações entre as espécies. Seriam, para Singer, "manifestações da ideologia de nossa espécie, isto é, como as atitudes que nós, animais mais dominantes, temos em relação a outros animais" , já que desde os tempos antigos o homem costumaria subjugar os outros animais, exercendo seu domínio sobre eles em práticas de crueldades disfarçadas como manifestações culturais e religiosas.

Para a maioria dos seres humanos não haveria que se pensar em tratar os demais animais como iguais, visto que o homem considerar-se-ia superior, não sendo importante para ele o sentimento dos animais não-humanos.

Singer, então, sustenta que a única hipótese de proteção verdadeira e efetiva aos animais não-humanos seria o vegetarianismo. Veja-se:

\footnotetext{
"A carne mancha nossas refeições. Por mais que disfarcemos, permanece o fato de que o prato principal chegou-nos de um abatedouro encharcado de sangue. Não tratada e não refrigerada, a carne logo se deteriora e exala mau cheiro. Quando a comemos, ela pesa no estômago, bloqueando nossos processos digestivos até que, dias mais tarde, lutamos para excretá-la".
}

Em relação aos experimentos em animais não-humanos, Singer propõe a teoria dos 3 $\mathrm{R}^{\prime}$ s: replacement, reduction e refinement (substituição, redução e refinamento) que seria basilar na reforma científica e implicaria em reduzir e, até mesmo, substituir, animais experimentais, bem como em reduzir ou abolir a dor ou demais sofrimentos durante manejo e procedimentos envolvendo tais seres. Implicaria, ademais, em ações positivas que pretenderiam melhorar o bem-estar dos animais usados em laboratório. 
Para Singer há alternativas de pesquisa que seriam mais válidas do que o uso de animais não-humanos e que podem ser aprimoradas para que não precisem sofrer em nome da ciência ou do "bem da humanidade". Acerca deste argumento, importante destacar a interpretação que Lori Gruen faz acerca do pensamento de Singer:

If a course of action will lead to more suffering than pleasure for all those who are affected by that action, then that action will be ethically impermissible. It doesn't matter if the suffering accrues to moles or men, or if the pleasure accrues to wombats or women. Once it is aggregated and compared, the course of action with the least suffering is the course of action ethically required (GRUEN, 2011, p. 52)

Assim, a capacidade de sofrimento de um ser vivo justificaria por si só a concessão de direitos aos animais não-humanos. Todavia, conceder direitos a tais seres não significaria conceder os mesmos direitos pertencentes a nós, humanos.

\subsection{Tom Regan e A Dignidade À Vida}

Tom Regan assume considerável relevância no debate acerca desta questão. Afirma Regan que há dificuldades encontradas pelos defensores da titularidade de direitos para os animais não-humanos, eis que muitos confundiriam ter direitos com ser bondoso, contudo afirma que ter direitos é algo muito além do que ser bondoso. Veja-se:

\footnotetext{
Direitos animais é uma ideia simples porque, no nível mais básico, significa apenas que os animais têm o direito de serem tratados com respeito. E é uma ideia profunda porque suas implicações têm amplas consequências. Quão amplas? Eis alguns exemplos de como o mundo vai ter de mudar, uma vez que aprendamos a tratar os animais com respeito.

Vamos ter de parar de cria-los por causa de sua carne.

Vamos ter de parar de mata-los por causa de sua pele.

Vamos ter de parar de treiná-los para que nos divirtam.

Vamos ter que parar de usá-los em pesquisas científicas.
}

O pensamento de Regan é caracterizado como "abolicionista", eis que não busca apenas uma reforma no sistema, mas sim acabar com o uso de animais em qualquer situação, por fim ao denominado "especismo", criando uma sociedade na qual todos os animais, e não apenas os humanos, possam gozar de igual atenção ética.

Nada justificaria, pois, o uso de animais, tanto para alimentação, pesquisas cientificas, quanto para entretenimento. Afinal, todos teríamos direito à liberdade, à vida e à integridade física, inclusive os animais não-humanos.

Todos seríamos, assim, sujeitos-de-uma-vida e, como tais, seríamos todos iguais por que: a) estaríamos todos no mundo; b) seríamos todos conscientes do mundo; c) o que acontece conosco seria importante para nós; d) o que acontece conosco (com nossos corpos, nossa liberdade ou nossas vidas) seria importante para nós, quer os outros se preocupem 
com isso, quer não; e) seríamos todos moralmente idênticos e f) seríamos todos moralmente iguais.

\begin{abstract}
Se olharmos a questão "com olhos imparciais", veremos o mundo transbordante de animais que são não apenas nossos parentes biológicos, como também nossos semelhantes psicológicos. Como nós, esses animais estão no mundo, conscientes do mundo e conscientes do que acontece com eles. E, como ocorre conosco, o que acontece com esses animais é importante para eles, quer alguém mais se preocupe com isto ou não. A despeito de nossas muitas diferenças, os seres humanos e os outros mamíferos são idênticos nesse aspecto fundamental, crucial: nós e eles somos sujeitos-de-uma-vida.
\end{abstract}

Quanto à delimitação dos animais que serão "sujeitos-de-uma-vida" - já que o autor afirma que animais não-humanos possuem tal direito independente de qualquer diferença existente entre os seres vivos - Regan propõe que caberá o ônus da prova a qualquer um que venha a responder negativamente a estas perguntas básicas, usando o exemplo dos pássaros "os pássaros estão no mundo? Conscientes do mundo? Conscientes do que acontece com eles? E o que lhes acontece é importante para eles, quer os outros se preocupem com isso, quer não?".

Caberá a quem responder negativamente a uma dessas perguntas provar os motivos pelos quais determinado ser não se encaixa na definição de “sujeito-de-uma-vida”. Assim, para o autor "sujeitos-de-uma-vida" seriam todos os seres que possuam:

(...) crenças e desejos, memória, e uma percepção do futuro que inclui o seu próprio; uma vida emocional, bem como sensações de prazer e dor; preferências - bem-estar - interesses; a habilidade de dar início a uma dada ação em busca de seus desejos e objetivos; uma identidade psicológica além do tempo; e um bem-estar individual no sentido de que sua vida experiencial ocorra bem ou mal para este ser, logicamente independente de sua utilidade para outros indivíduos, ou de ser alvo dos interesses de outrem.

Desta forma, os critérios para classificar um ser como "sujeito-de-uma-vida" funcionariam onde os demais critérios para aferir igualdade supostamente falham. Os "sujeitos-de-uma-vida" possuiriam percepção de si, e o fato de estarem vivos por si só garantiria tratamento com respeito, desde que possuam valor inerente.

Em que pese Regan considerar que alguns (senão a maioria) dos animais não-humanos seriam "sujeitos-de-uma-vida", deixa claro que tal afirmação não significa dizer que todos sem exceção o são: "a perspectiva dos direitos oferece fundamentos criteriosos para crer nos direitos de alguns animais não-humanos, sem que tenhamos de acreditar que todos os animais não-humanos, incluindo as amebas, têm direito" .

O autor ainda afirma que não seria possível traçar uma linha objetiva entre quais animais são sujeitos-de-uma-vida quais não. Afinal, a consciência, que seria comum a todos os "sujeitos-de-uma-vida", seria um dos grandes mistérios da própria vida. Veja-se: 
Quer os estados mentais sejam idênticos a estados cerebrais, quer não o sejam, temos provas esmagadoras de que a existência de quaisquer estados mentais pressupõe a existência de um sistema nervoso central intacto e funcional, bem como de atividade do cérebro acima do tronco cerebral. Ninguém pode saber realmente, com toda certeza, qual o ponto exato da escala filogenética em que emerge a base fisiológica da consciência, nem qual o ponto exato em que esta desaparece."

Regan, é importante ressaltar, parte de um conceito deontológico de direito. Ei-lo:

\begin{abstract}
Entendidos num sentido mais estrito, os direitos são um traço distintivo das perspectivas éticas de caráter deontológico - não são compatíveis, portanto, com todas as perspectivas éticas. Quando um deontologista diz que as pessoas inocentes têm, por exemplo, o direito à vida, está a afirmar que é errado matar intencionalmente uma pessoa inocente mesmo que isso seja necessário para produzir um maior bem, como salvar várias pessoas inocentes. Concebidos deontologicamente, os direitos são assim limites éticos àquilo que podemos fazer aos outros não só quando perseguimos objetivos pessoais, mas também quando temos em vista o bem-estar social ou outro fim louvável mais amplo, como a conservação ambiental ou o alargamento do conhecimento. Para nos referirmos a essa forma de conceber os direitos, podemos falar de direitos deontológicos. Estes, note-se, são essencialmente negativos: respeita-los é não interferir de certas formas nas vidas dos indivíduos que os possuem. É por isso que por vezes são comparados a sinais invisíveis de passagem proibida.
\end{abstract}

Desta forma os "sujeitos-de-uma-vida" teriam deveres morais com outros "sujeitos-de-uma-vida", que seriam tanto positivos, quanto negativos, de não maleficência, portanto.

Em síntese, Regan sustenta que os "sujeitos-de-uma-vida" possuiriam uma percepção de si mesmo e que o fato de estarem vivos já garantiria, por si só, a possibilidade de possuírem direitos, positivos e negativos, perante os demais "sujeitos-de-uma-vida".

3.7 Martha Nussbaum e as Competências como atributos suficientes para o RECONHECIMENTO DE DiReitos AOS ANimais NÃO-HUMANOS

Martha Nussbaum parte do pressuposto que os humanos dividimos e compartilhamos o mundo com outras criaturas inteligentes e que não haveria motivo evidente que justificasse que ideias como justiça básica, titularidade e Direito não pudessem ultrapassar a barreira das espécies.

Critica a abordagem de Kant e de John Rawls por valorizarem, de modo equivocado, a racionalidade, a capacidade para escolha moral e a assimetria de poder entre humanos e não-humanos, bem como por identificaram, no máximo, um dever de compaixão dos humanos para os demais seres. Explica que o dever de compaixão seria uma visão limitada e equivocada por envolver o pensamento de que a pessoa que sente a compaixão por alguém que está sofrendo significativamente não se sente responsável por tal sofrimento, pelo que a compaixão não envolveria a noção de responsabilização pelo sofrimento causado a outrem. A autora, então, afirma que a questão não seria de compaixão, mas de justiça, conceito este que envolveria a noção de que a criatura lesada teria o direito ou o crédito moral, básico e 
urgente, de não ser tratado de modo a causar-lhe sofrimento.

Em seguida, em que pese reconhecer a contribuição do utilitarismo para o reconhecimento de direitos aos animais não-humanos, critica referida abordagem especialmente por dos de seus elementos, o ranking de somatório e o hedonismo. O primeiro elemento impediria que fossem, antecipadamente, obstados resultados extremamente duros para com um dado grupo ou classe. Assim, nem o especismo nem a escravidão poderiam ser excluídas previamente, sem que fosse, pois, realizada a soma e obtido o resultado social único empírico de bem-estar médio ou total. O segundo elemento (hedonismo), por considerar o prazer ou a dor como elementos isolados, seria incompleto. Não apenas pela dificuldade em se medir o prazer ou a dor, nem, também, por existirem prazeres ruins, mas porque existiriam dores ou prazeres inconscientes.

A abordagem das competências, portanto, pretenderia partir do pressuposto de que qualquer tipo de vida possui profundas necessidades e habilidades, pelo que seu objetivo básico seria atender a necessidade de uma rica pluralidade de atividades vitais. Não satisfazê-las seria, tal como pensava Aristóteles, um tipo de morte prematura. Deste modo, teríamos obrigações de justiça para com os animais não-humanos, obrigações que não seriam sequer secundárias ou posteriores em relação às que temos para com os humanos. E porque os seres humanos exercemos um domínio sobre os demais seres, nosso ordenamento jurídico deveriam incluir "robustos compromissos políticos positivos para com a proteção dos animais".

A teoria de Nussbaum reconhece haver diferenças moralmente relevantes entre as diversas formas de vida, indaga, todavia, quais as diferenças que devem ser levadas em consideração na ora de fixarmos direitos e obrigações? Aduz que não se pode levar em conta apenas a sensibilidade, como o fazem Singer e Bentham eis que poderia haver frustação de interesses desprovida de percepção consciente. Não se poderia, ademais, levar em conta a espécie, no sentido de que o pertencimento a uma espécie seria moral e politicamente irrelevante para o reconhecimento ou atribuição de direito.

Para Nussbaum dever-se-ia levar em conta a "prosperidade de aptidões (inatas)", no sentido de que cada espécie prospera a seu próprio modo.

Salienta que se no universo das relações inter-humanas não faria sentido a distinção tradicional entre obrigações positivas e negativas, na medida em que todas as competências humanas necessitam de um suporte afirmativo, geralmente englobando a atuação estatal. No universo das relações entre humanos e não-humanos, todavia, poderia parecer haver sentido na referida distinção. Assim, pareceria coerente afirmar que os humanos teríamos o dever de não praticar certos danos notórios aos não-humanos, mas que não estaríamos obrigados a sustentar o bem-estar de todos eles, assegurando-lhes, por exemplo, comida, abrigo ou serviços de saúde adequados.

Todavia, conforme acredita a autora, referida distinção entre positividade e negatividade, mesmo no campo das relações entre humanos e não-humanos não poderia ser completamente aceita. Afinal, um grande número de animais já viveria sob o controle direto de humanos (os domésticos, os que estão em zoológicos, os de produção...) e, nestes casos, existiria deveres diretos e positivos especialmente com a alimentação e saúde de tais seres. Os deveres positivos também existiriam sempre que os humanos interferíssemos nos habitats dos demais animais. 
Para a autora, não há dúvidas no sentido de que uma importante área de responsabilidade humana, perante os demais seres, seria aquela que envolva a abstenção de ações maléficas. Todavia, fundamental seria constatarmos que as obrigações não parariam por aí. Indaga, em seguida, qual, então, seria a verdadeira extensão de nossas obrigações? E como poderíamos harmonizá-las com o respeito devido à autonomia das espécies?

A resposta, sustenta, estaria ligada ao desenvolvimento de um paternalismo inteligente, "bastante sensível às diferentes formas de prosperidade que as diferentes espécies perseguem".

Neste sentido, a autora cita uma lista de dez competências inerentes aos humanos, sendo elas: a) Vida; b) Saúde corporal; c) Integridade corporal; d) Sentidos, imaginação e pensamento; e) Emoções; f) Racionalidade prática; g) Associação; h) Outras espécies; i) Participar de atividades lúdicas e j) Controle sobre o ambiente individual.

Após, identifica em tais competências humanas uma base adequada para elaboração de alguns princípios políticos fundamentais básicos não-humanos.

Em relação à vida, informa que esta competência deve ser protegida mesmo que os animais não demonstrem ter interesse consciente da importância de tal competência, afinal, todos teríamos o direito de dar continuidade às nossas próprias vidas. Assim, deveriam ser obstadas as martes por esporte, para obtenção de itens de luxo e permitidas as mortes vinculadas a eutanásia, ao controle de populações e, com cuidados especiais para que a morte seja indolor e precedida de uma vida saudável e em condições de liberdade, as mortes vinculadas à alimentação.

No que pertine à saúde corporal, salienta que o direito a uma vida saudável seria um dos direitos mais básicos dos animais, pelo que, em relação aos animais que estejam diretamente sob o controle humano, inclusive os para fins de alimentação, deveriam ser banidos comportamentos como o confinamento, crueldade ou maus-tratos.

Em face da competência denominada integridade corporal, que se aproximaria bastante da anterior, sustenta que os animais não-humanos deveriam ficar livres de maus tratos, violência, abusos ou negligências que impliquem tratamento prejudicial às suas integridades Corporais, independente de referido tratamento causar dor.

Em face das competências de sentidos, imaginação e pensamentos, fundamental seria garantir aos animais não-humanos o acesso às suas fontes de prazer, banindo os tratamentos cruéis e abusivos.

No que pertine às emoções, após asseverar que a grande maioria dos animais possuiria ampla capacidade de emoções, tendo capacidade de sentir medo, gratidão, alegria e, até mesmo, a compaixão, devem ter direitos de estabelecer vínculos, amar e cuidar dos outros, pelo que estariam vedadas as diversas formas de confinamento forçado.

A racionalidade prática exigiria que analisássemos cada caso para sabermos até que ponto será necessário, até que ponto a criatura tem a capacidade de estabelecer objetivos e projetos de planejamento da sua vida.

Ao preservamos a competência de associação, teríamos o dever de ofertar oportunidades para que os demais seres formem vínculos e engajarem-se em formas características de entrosamento e inter-relacionamentos, inclusive com humanos. 
A autora defende, ainda, a importância dos demais seres de participarem de atividades lúdicas, em espaço adequado e com a presença de membros de outras espécies, dentre outros aspectos.

Nussbaum encerra o rol das competências discorrendo acerca do controle sobre o ambiente individual, defendendo que os animais não-humanos devem ter o direito de fazer parte de uma comunidade política estruturada de modo a respeitar-lhes e que esteja comprometida em tratar-lhes de forma justa. Devem ser tutelados por humanos que possam ingressar em juízo para reivindicar seus direitos.

Esclarece, ainda, que a lista de competência não se esgota nas mencionadas acima, sendo, portanto, aberta. Veja-se:

Em geral, a abordagem das competências sugere que é apropriado para as nações incluir em suas constituições ${ }^{67}$ ou outras declarações ${ }^{68}$ de princípios fundadores um compromisso para com os animais como sujeitos de justiça política e um compromisso de que os animais serão tratados com dignidade. A constituição pode também detalhar alguns dos próprios princípios gerais sugeridos por esta lista de competências. $\mathrm{O}$ restante do trabalho de proteção dos direitos dos animais poderá ser promovido por legislação adequada e por casos judiciais que demandem a efetiva aplicação da lei, onde ela não é aplicada. Ao mesmo tempo, muitas das questões cobertas por esta abordagem não podem ser tratadas por nações de modo isolado, podendo apenas ser endereçadas por meio de cooperação internacional. Portanto, também são necessários acordos internacionais que comprometam a comunidade mundial com a proteção dos habitats animais e com a erradicação de práticas cruéis.

Ao final, indagando acerca de como proceder em caso de conflito entre as competências humanas e não-humanas, salienta que a presença de tal conflito sugeriria que a sociedade, em algum momento, fez algo errado, deixando de planejar, atentamente, um mundo onde o exercício de tais competências não seja conflituoso.

Salienta que parte do tratamento cruel, por exemplo, poderia ser eliminada sem perdas significativas aos interesses humanos. Acentua que a questão adquire grau de delicadeza maior em relação aos animais destinados à alimentação (ninguém, ao certo, saberia o impacto sobre o meio ambiente causado por uma alteração total para fontes vegetarianas de proteínas ou, tão pouco, até que ponto tal dieta poderia sem compatibilizada com a saúde humana) ou à pesquisa (muito embora possam ser identificados testes nitidamente desnecessários, como os com os coelhos, destinados ao uso de cosméticos, haveria pesquisas importantes e com consequências relevantes para a vida e a saúde humanas e que, assim, deveriam permanecer com os cuidados que menciona. Defende, já na parte final de seu texto, a constante discussão pública acerca de tais temas.

Por fim, Nussbaum assevera que só existirá uma justiça verdadeiramente global quando os seres humanos pararem de buscar apenas a qualidade de vida para outros seres humanos, passando a estender tal preocupação a todos os seres sensíveis que habitam o mundo. Seres estes com os quais nossas vidas estão entrelaçadas de forma complexa e dependemos uns dos outros de forma intrínseca. Somente desta forma alcançaremos a justiça global verdadeira, acredita a autora. 


\section{${ }_{6}$ Conclusão}

Diante o exposto, fica evidente a profunda dissonância entre os grupos de autores que atribuem ou reconhecem, ou não, a titularidade de direitos aos animais não-humanos.

Já se pode afirmar que as teorias contratualistas tutelam os animais não-humanos de maneira indireta, eis que sua proteção está vinculada a lesões aos interesses dos humanos e não, propriamente, ao reconhecimento de uma dignidade intrínseca.

Parece, ademais, ser possível afirmar que as teorias de viés utilitarista, ao reconhecerem que tais seres podem gozar de capacidade de sofrer, ofertam um maior nível de proteção, ainda que possam colocar, na prática, as necessidades humanas acima das dos demais animais, além de poderem considerar plausível determinado sofrimento se for compensado por uma maior satisfação para a humanidade.

Por seu turno, a abordagem das competências procura defender a ideia de que os animais não-humanos sejam portadores de certas competências que precisarão ser realizadas e garantidas por direitos.

Destarte, pretendeu-se deixar assentado o nítido conflito entre a existência humana, mais precisamente em relação a sua atual forma subsistência e a efetiva proteção jurídica dos animais não-humanos, já que o reconhecimento de direitos a tais seres certamente implicará em ônus importantes a nós, humanos.

\section{Notas}

1 REGAN, Tom. Objeções e Respostas. In GALVÃO, Pedro (Org.). Os Animais têm Direitos? Perspectivas e Argumentos. Lisboa: Dinalivro, 2010, p. 97 a 120; PALHANO, Jerson José Darif e SANCHES, Mário Antonio. Sobre os animais não humanos: um resgate teológico. Revista Bioethikos. Centro Universitário São Camilo. 2012. 6(3): p. 287 a 299.

2 MACINTYRE, Alasdair. Dependent Rational Animals. Chicago: OPEN COURT, 1999, p. 12.

3 SINGER, Peter. Defense of Animals the Second Wave. Oxford: Blackwell Publishing, 2006, p. 4.

4 SINGER, Peter. Op. Cit.p. 5.

5 RACHELS, James. Darwin, Espécie e Moralidade. In GALVÃO, Pedro (Org.). Os Animais têm Direitos? Perspectivas e Argumentos. Lisboa: Dinalivro, 2010, p. 193/194.

6 SUSTEIN Cass. Os animais podem processar? MOLINARO, Carlos Alberto; et al (Org). A Dignidade da Vida e os Direitos Fundamentais para além dos Humanos: Uma Discussão Necessária. Belo Horizonte: Fórum, 2008, p. 12.

7 KANT, Immanuel. Anthropology from a Pragmatic Point of View. Ed. and trans. Mary Gregor. The Hague: Martinus Nijhoff, 1974, p. 127.

8 SALT, Henry. Animal rights. Pennsylvania: Society for Animal Rights, 1980, p. 165.

9 Apud REGAN, Tom. The case for Animal Rights. California: University of California Press, 1983, p. 100.

10 Ibidem, p. 101.

11 Apud FELIPE, Sônia T. Ética e experimentação animal. Fundamentos abolicionistas. Florianópolis: Editora UFSC, 2014, p. 123. 
12 COHEN, Carl. Os Animais têm Direitos? In GALVÃO, Pedro (Org.). Os Animais têm Direitos? Perspectivas e Argumentos. Lisboa: Dinalivro, 2010, p. 63 a 68.

13 Ibidem, p. 70.

14 Ibidem, p. 74.

15 Ibidem, p. 68/69.

16 Idem.

17 BENTHAN, Jeremy. Introduction to the Principles of Morals and Legislation. Reino Unido: Courier Corporation, 2012, p. 122.

18 LOW, Philip, The Cambridge Declaration on Consciousness. Cambridge, 2012.

19 GRUEN, Lori. Ethics and Animals. An Introduction. United Kingdom: Cambridge University Press, 2011, p. 1.

20 BROOM, Donald M.; FRASER, Andrew F. Comportamento e bem-estar de animais domésticos. São Paulo: Manole, 2007, p. 13.

21 Ibidem, p. 6.

22 SINGER, Peter. Libertação Animal. São Paulo: Martins Fontes, 2013, p. 5.

23 Ibidem, p. 9.

24 Ibidem, p. 327.

25 SINGER, Peter. Defense of Animals the Second Wave. Op. Cit., p. 49.

26 SINGER, Peter. Libertação Animal. Op. Cit., p. 11.

27 Ibidem, p. 267.

28 Ibidem, p. 261.

29 SINGER, Peter. Defense of Animals the Second Wave. Op. Cit., p. 96.

30 GRUEN, Lori. Op. Cit., p. 52.

31 REGAN, Tom. Jaulas Vazias: encarando o desafio dos direitos animais. Porto Alegre: Lugano, 2006, p. 12.

32 GRUEN, Lori. Op. Cit., p.196.

33 REGAN, Tom. Jaulas Vazias: encarando o desafio dos direitos animais. Op. Cit., p. 62.

$34 \quad$ Ibidem, p. 72.

35 Ibidem, p. 73.

36 Ibidem, p. 245.

37 REGAN, Tom. Objeções e Respostas. Op. Cit., p. 99.

38 Ibidem, p.103.

39 Ibidem, p.10/11.

40 NUSSBAUM, Martha C. Para além de "compaixão e humanidade" - Justiça para animais não humanos. MOLINARO, Carlos Alberto; MEDEIROS, Fernanda Luiza Fontoura de; SARLET, Ingo Wolfgang; FENSTERSEIFER, Tiago (Org). A Dignidade da Vida e os Direitos Fundamentais para além dos 
Humanos: Uma Discussão Necessária. Belo Horizonte: Fórum, 2004, p. 87.

41 Ibidem, p. 89/92.

42 Ibidem, p. 92/98.

$43 \quad$ Ibidem, p. 99.

44 Ibidem, p. 102.

45 Ibidem, p. 103.

$46 \quad$ Ibidem, p. 107.

47 Ibidem, p. 106.

48 Ibidem, p. 108.

$49 \quad$ Ibidem, p. 111/112.

$50 \quad$ Ibidem, p. 112.

51 Idem.

52 Ibidem, p. 113.

$53 \quad$ Ibidem, p. 114 a 116.

$54 \quad$ Ibidem, p. 117.

55 Ibidem, p. 117/118.

56 Ibidem, p. 118.

57 Ibidem, p. 118/119.

58 Ibidem, p. 119/120.

59 Ibidem, p. 120.

60 Ibidem, p. 120/121.

61 Ibidem, p. 122.

62 Idem.

63 Ibidem, p. 123.

64 Ibidem, p. 123.

65 Ibidem, p. 124/125.

66 Ibidem, p. 125/126.

67 Tal assunto será objeto do tópico seguinte, onde será tratado mais detalhadamente, com abordagem na visão constitucional, e concessão de direitos aos animais não humanos. Para maior aprofundamento ler tópico 3

68 Tal assunto será tratado no tópico 4 